This report wes prepared as an account of work sponsored by an agency of the United States Government. Neither the United Stales Government nor any agency thercol, nor any of their employees. makes any warranty, express or implied, or assumes any legel linbility or responsibility for the accuracy, completesess, or usefulness of any informetion, apparatus, product, or process disclosed, or represents that its use would not infringe privately owned rights. Reference herein 10 any specific comıercial product, process, or service by trade name, trademark, manufacturer, or otherwise doss not necessarily constitute or imply its endorsement, recommendetion, of favoring by the United States Government or any agency thereof. The views and opinions of authors expressed herein do not necessarily state or reflect those of the United States Government or any agency thereof.

\title{
THUN FILM SYNTHESIS USING MINIATURE PULSED METAL VAPOR VACUUM ARC PLASMA GUNS
}

\author{
X. GODECHOT*, M. B. SALMERON, D. F. OGLETREE, J. E. GALVIN, \\ R. A. MACGIIL, M. R. DICKINSON, K. M. YU AND I. G. BROWN
}

\author{
Lawrence Berkeley Laboratory \\ University of Califomia \\ Berkeley, CA 94720
}

Paper presented at the Materials Research Society, Spring Meeting, San Francisco, CA, April 16-21, 1990.

- On leave to LBL from SODERN, 1 Ave. Descartes, 94451 Limeil-Brevannes, France. This report has been reproduced directly from the best available copy. This work was supported by the Director, Office of Energy Research, Office of Fusion Energy, Development and Technology Division, of the U.S. Deparment of Energy under Contract No. DE-AC03-76SF00098. 


\title{
THIN FILM SYNTHESIS USING. MINLATURE PULSED METAL VAPOR VACUUM ARC P'LASMA GUNS
}

\author{
X. GODECHOT*, M. B. SALMEiRON, D. F. OGLETREE, J. E. GALVIN, \\ R. A. MACGILL, M. R. DICKINSON, K. M. YU and 1. G. BROWN
}

Luivrence Berkeley Laboratory

University of California

Berkeley, CA 94720

\section{AHSTIRAC'}

Metallic contings can be fabricated usiıg the intense plasma gencrated by the metal vapor vicuum arc. We have made aud tested an eimbodiment of vacuum are plasma source that operates in a pulsed mode, thereby acquiring precise control over the plasina flux and so also over the deposition rate, and that is in the form of a miniature plasma gun, thereby allowing deposition of metalic thin films to be carried out in confined spaces and also allowing a number of such guiss to be clustered together.

The plasma is created at the cathode spots on the metallic catliode surfitce, and is highly ionized and of directed energy a few tens of electron volts. Adhesion of the filin to the substrate is thus good. Virtually all of the solid metals of the Periodic Table cin be used. including highly refractory melals like tantalum and tungsten. Films, including multilaycr thin films, can be fabricated of thickness froun Angstroms to microns. We have carried out preliminary experiments using several different versions of miniature, pulsed, metal vapor vacuum arc plasma guns to fabricatc metallic thin films and aublilayers.

Here we describe the plasma guns and their operation in this application, and present exiumples of some of the thin film structures we have fibricated, including yturium and platimum filus of thicknesses from a few hundred Angstrons up to 1 micron and an ytrimm-cobalt multilayer structure of layer thicksiess about 100 Angstrons.

\section{INTRODUCT:ON}

The technology for the formation of thin films and compositionally medulated multiliyer structures has mude great advances, and an array of such tecluniques is aviilable to tlic experimenter. These tecluniques include sputtering [1], electron beim evaporation [2], molecular beam cpitaxy (MI3L) [3], ion beam deposition [4,5], and lascr ab!ation deposition 16.7|. There is interest in techniques for the deposition of metallie thin films also, or of multilayer structures in whiclt one or more of the eomponents is a metal [8-10]. The metal] vapor vacuutu arc [11] is a kind of plasma discharge that takes place between metallic electrodes in a high vacuum environurent and that is a prolific producer of dense metai plasina. Vacum anc plasma sources are attractive devices for the deposition of metallic aloin fifms $(12,13\}$. '1'hese kinds of sourtes produce intense fluxes of highly ionized metal plasma which when condensed form highly adiserent and dense thin filus. The metal vapor vacutum ate plasma discharge has been used widely for deposition of various metal coutings in a vacuun cuviromnent atld for the formation of TiN protective contings [14,15], atid industrial are somec deposition exuipment is readily available on the market [16]. The vacumu arc is commonly also called a 'cathedic arc'. Catlodic arc facilities are large pieces of cefuipment and

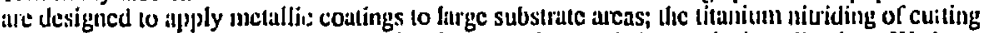
tools alld ollier components in a large batch proxessing mode is a lypicial application. We lave laken the valcum arc techlology to the other extreme - miniature source with fine control over lac deposition flux - and hitse thereby developed a cool which could find application for the formation of metallie thin films and multilayers aver refatively smatl areas (alwough this paranseter could readily be seilled up) and with thickness and composilion tailoring (lown to the montslayer level. The method is particularly simple and inexpensive, and is well suited for thin film research involying the preparation of mamy experimental samples, as the sch-up time required is minimal and the anount of material consumed is very small. 


\section{DESCRIPTION OF THE PLASMA GUNS}

The fundamental phenomenon which drives the vacuum arc is that of cathode spot formation - minute regions of intense current concentration which reside on the surface of the cathode and at which the solid cathode material is vaporized, ionized, and injected into the inierelectrode arc region. The current density at the cathode spots is of order $10^{6} \mathrm{~A} / \mathrm{cm}^{2}$ over a spot size of order microns. A typical vacuum are discharge night consist of from one to many dozens of sucls spots. A very complete review of the entire field of metal vapor are disclarges has been given by Lafferry [11] and a review of cathode spot behavior has been given by Lyubimov and Rakhovskii [17].

In the method described here, a miniature metal vapor vacuum are plasma source is used to generate an intense flux of metal plasma in a vacuum environment. The dense metal plasma plumes away from the cathode at which it is created, through a central hole in an annular anode, and toward the substrale on which the film is to be fornied. The plasma source is repetitively pulsed, and a thin film can be deposited over an area of several scuare centimeters in a time of several minutes.

The arc discharge is driven by a simple L-C pulse line of impedance $1 \mathrm{Ohm}$ and pulse length 250 microseconds. The line is charged to a voltage of up to several hundred volts with a small de pou er supply. A high voltage puise applied to a trigger electrode initiates a surface spark discharge between the coaxial trigger electrode and the central cathode, which in turn causes the main anode-cathode circuit to close due to the spark plasma, and the vacuum arc proceeds. Typically the source is operated at a repetition rate of up to several pulses per second, a rate which is limited by heat removal considerations.

The properties of the plasma generated by this kind of plasma gun, as reflected in the extracted ion beam, have been extensively studied as part of the LBL MEVVA ion source R\&D program. The MEVVA ion source has been fully described elsewhere [18-20]. The source works well ivilh vinually all solid metals of the Periodic Table; we have operated the source and measured the ion claurge state distributions using 48 different metallic elements $[21,22\}$ and a range of alloys and compounds [23].

A photograph of two slightly different embodiments of miniature plasnu gun is shown in Figure 1. Both of these guns have been used.
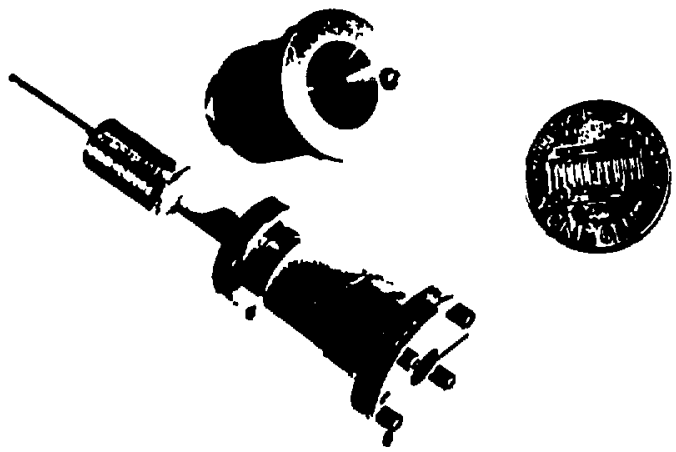

Fig. 1 Photograph of two versions of miniature metal vapor vacuum arc plusma gun. 


\section{RESULTS}

In the preliminary work described here we have produced several different kinds of thin film structures on a Si substrate material. The film composition is determined by the choice of cathode metal. Films of $\mathrm{Pt}$ and $\mathrm{Y}$ were synthesized, and by using an array of two miniature plasma guns operating with different metallic cathodes we formed an alternating Co-Y multilayer structure. The guns were fired in the appropriate sequence to build up the required multilayer composition. We operated the plasma guns with an arc current of between 30 and $100 \mathrm{~A}$, and the are voltage was approximately 20 Volts. The Si substrate was biased up to -60 Volts and the plasma ion current measured at the substrate was in the range $200 \mathrm{~mA}-1 \mathrm{~A}$. The plasma gun and substrate were mounted in a large vacuunt vessel with a separation distance between them of $2-3 \mathrm{~cm}$, for these experiments; this geometry produced a film of diameter on the silicon wafer of approximately $3.4 \mathrm{~cm}$. The operating pressure was below $5 \times 10^{.6}$ Torr. Because no cooling was provided it was necessary to operate with a low repetition rate, from about 1 pulse per 3 seconds to 3 pps. The thickness of the film was controlled by the number of shots, varied here between 1 and several thousand.

We used a number of different diagnostic methods to examine the films deposited: exsitu RBS, SEM, TEM, Auger and in-situ XPS. A disadvantage of ex-situ methods is pos"deposition oxidization of the film. The TEM data show that filnss 2 - 3 monolayers thick of $P t$ on Si were deposited by 50 pulses of the gun. In Figures $2 \mathrm{a}$ and $2 \mathrm{~b}$ we show the RBS spectra obtained from a Pt film ( 900 sloots) and an Y film (5900 shots), sespectively.
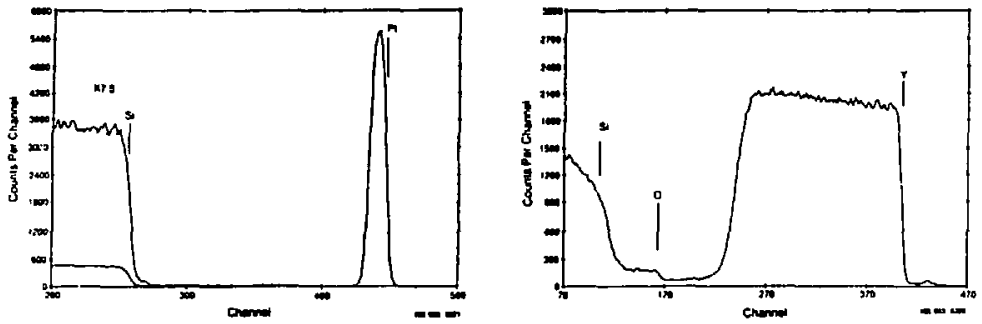

Fig. 2. RBS spectra for (a) Pt film on Si obtained after 900 gun shots; (b) $Y$ film on $\mathrm{Si}$ obtained after 5900 gun shots.

The purity of the film is better than $99 \%$. This was checked in-situ with XPS as shown in Figure 3. All the Pt peaks can be seer, and no metal impurity peaks were detected. The oxygen and carbon peaks are probably due to the use of an unclean wafer and residual gas in the modest yacuum.

Two Pt films were deposited, using 205 and 900 shots to produce doses of $2.8 \times 10^{16}$ atom/cm $/ \mathrm{cm}^{2}$ and $1.1 \times 10^{17} \mathrm{atom} / \mathrm{cm}^{2}$ (40 and 160 Angstroms thickness), respectively. The growth rate was approximately 16 shots per monolayer or 0.2 Angstroms per shot. This is in accordance with the TEM observations. With yturium we produced a thicker film, using 5900 shots. During storage at atmospheric pressure the film oxidizes. Using RBS (Figure 2b) we measured an $Y$ dose of $1.35 \times 10^{18} \mathrm{atom} / \mathrm{cn}^{2}$ and an $\mathrm{O} / \mathrm{Y}$ ratio of 1.29 . We can estimate that before oxidation the $Y$ film growth rate was 5 shots per monolayer or 0.8 Angstroms per shot. Like the $\mathrm{Pt}$ (films, the $\mathrm{Y}$ film is quite pure apar from oxidation.

In Figure 4 we show the Auger depth profile results for the Co-Y multilayer thin film structure. 250 shots were used to make each liyer. The $C o$ and $Y$ layers are estimated to be 45 and 200 Angstroms thick, respectively. The interface sharpness is equal to or better than the resolution of the Auger depth profile $(20 \AA)$. The deposition rate for Co is close to that for $\mathrm{Pl}_{1}$ (approximately 0.2 Angstroms per shot) and that for $Y$ is the same as ineasured for the thicker $Y$ layer (approximatcly 0.8 Angstroms per shot). 


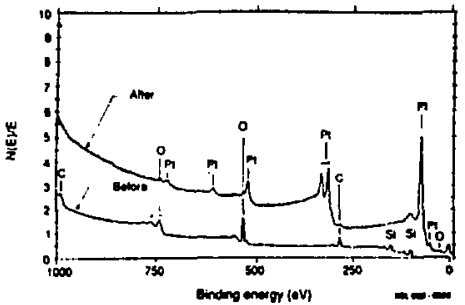

Fig. 3. XPS spectrum for a Pt film on Si obtained after 205 gun shots.

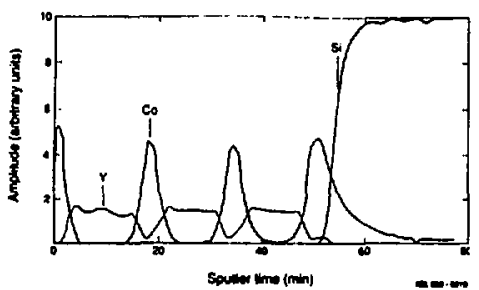

Fig. 4. Auger depth profile of $\mathrm{Co}-\mathrm{Y}$ multilayer structure.

\section{DISCUSSION}

We have demonstrated that the miniature metal vapor vacuum arc plasma gun described here provides a valuable tool for the synthesis of metallic thin films and multilayers. Operation in a pulsed mode permits control of the film deposition to within a tenth of a monolayer, or much less by appropriate choice of geometry. The synthesis of films of monolayer or submonolayer thickness is simple and can be done in a matter of minutes or less. Films of thickness a few tenths of a micron can also be formed. It luas been established in related work $[21,22]$ that the plasma gun operates well with nearly all the metallic elements of the Pcriodic Table, and it is possible to synthesize thin films and multilayers of any metuls or any combination of metals. Alloys, chemical compounds, and some semiconductors can also be employed [23]; we have for example used - stainless steel, brass; FeS, PbS, TiN, SiC, WC. UC; $\mathrm{Si}, \mathrm{C}$.

Because of the directed energy of the plasma stream (typically several tens of electron volts). film adhesion to the substrave or adhesion of interleaving multilayers to each other is good. That the deposition flux is pulsed and that the timing of the plasma pulses can be controlled to the microsecond level could provide a means for carrying out some novel experiments. For example, highly reactive films can be deposited and immediately covered with another film. By using two plasma guns operating simultuneously it shouid be possible to form novel non-equilibriun materials. Finally, because the deposition flux is in the plasma state and contains multiply charged and highly excited ions, some novel chemistry effects might be expected and could perhaps be harnessed.

Along with the metal plasma that is generated there is also a flux of macroscopic droplets, of size typically in the broad range $0.1-10$ microns [24-26]. We have exanined the films prepared here under SEM and have found a snuall but real 'nacroparticle' contanination on the film surface (Fig.5).

The origin of these particles is at the cathode spot itself and results from the intense heating of the cathode material beneath the spot. A volume of material is rendered noolten by the arc and the pressure gradient in the vicinity of the arc expels molien droplets along with the vapor. The volume of molten material formed is less for higher melting point matcrials, atnd the macroparticle contamination is observed to be less for cuthode materials of higher melting point. For sume applications, useful films can be made by proper selection of cathode material. In the case of a carbon cathode (and also sone olher elements and compounds), even larber solid particles use ejected from the arc spor. These result from the porous nature of most solid carbon materials. Gas trapped in voids in the eathode causes pressure gradients which blow solid pieces of cathode from the source.

There is a natural separation of the wanted plasma flux from the unwanted macroparticle flux by virue of the fact that the plastna flux is peaked in the direction normal to the cathode surface while the macroparticle flux is peaked in a direction close to parallel to the 


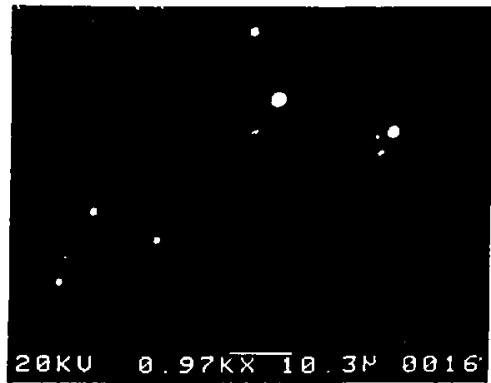

Fig. 5. SEM micrograph of nucroparticles lying on a Pt filn.

cathode surface. For those applications for which the macroparticle generation is severe or for which absolutcly particle-free films are required, a magnetic filter can be used, as has becn described by several workers [27-29]. The macroparticles travel in approximately straight line trajectories from the cathode because their velocitics are quite high, up to $800 \mathrm{n} / \mathrm{sec}$ [30]. An effective filter is tluus an optically dense channel which permits plasma transmission with good efficiency. One simple configuration, that could be suitable for some applications, is a curved tube or pipe which precludes line-of-sight nucroparicles from passing through it, while allowing a relatively high transmission of plasma by virtue of an axial magnetic field which ducts the plasma through die filter [27.31-33]. There is in general a loss of plasma through the filter and a consequent decrease in deposition rate at the other end.

We are presently developing a device with which we will be able to form multilayers composed of up to 10 different metal species in a single batch. This thin film symbesis device will include 10 cathodes and a $r$ :ating substrate holder. We will be able to make, for example, high-Z/low-Z multilayer structures and $Y$-Ba-Cu structures with each latyer from a few Angstroms to several tenths of microns.

\section{CONCLUSIONS}

We have developed and tested a miniature metal vapor vacuum arc plasmn gun. Prelininary results demonstrate the ability of this device to control the growth of metallic thin films very accurately, to within a few tentlss of an Angstrom, of thickness from sub-nonolityer up to microns. It is possible to produce filnss of nearly all the metallic elements of the Periodic Table. Using an array of such guns, multilayer structures of a wide range of metallic components can be fabricated.

\section{ACKNOWLEDGEMENTS}

This work was supported by the U.S. Departnent of Energy under Contract No. DE-ACO3. $76 S F 00098$.

* On leave to Lawrence Berkcley Laboratory from SODERN, 1 Ave. Descartes, 94451 LimeilBrevamins, France.

\section{REIEKENCES}

1. IV, W. Barbec, Jr, l'roc. SPIE S03, 3 (1985)

2. E. Spiller, AlP ['roc. $25,125(\overline{19 B I})$

3. E. H. C. P'irker, editor, "The Technology and Pluysics of Molecular Beam Epitaxy", Henum Press, New York, 1985

4. B. R. Appleton, R. A. Zuhr, T. S. Noggle, N. Herbots, S. J. Pennycook and G. D. Alion, MRS Bulletin 12, 52 (1987) 
5. J. M. E. Haner, in "'. Thin Film Processes", edited by J. L. Vossen and W. Kern, Actudemic press, New York, 1978

6. J. P. Rebonillat, B. Michelutt, Y. Souche, J. P. Gavigan, D. Givord and A. Lienard, in "Growth, Chartcterization and Propentics of Ulurathin Matgnetic Filmss and Multiluyers", (B. T. Jonker, J. P. Ilerentaus and E. E. Marinero, editors), MRS Symposium Procecdings Vol. 151, p. 259 (1989).

7. "Liser Ablation for Thin Film Deposition", Symposium N, this conference.

8. C. M. Falco, in "Physics, Fabrication, and Applications of Multilayered Structures", edited by P. Dhez and C. Weisbuch, Plenum Press, N.Y., 1988.

9. T. W. Larbee, Jr., in "Synthetic Modulated Structures", edited by L. L. Chang and B. C. Geissen, Academic Press, Orlando, Fla, 1985.

10. T. W. Barbec, Jr., Opt. Fing. 25, 898 (1986).

11. "Vacuum Arcs - Theory and Application", edited by J. M. Lafferty, Wiley, New York, 1980.

12. R. L. Boxman, S. Goldsmith, S. Shalev, H. Yaloz and N. Brosh, Thin Solid Films 139 , 41 (1985).

13. D. M. Sinders, "Review of Ion Based Conting Processes Derived from the Cathodic Arc", J. Vac. Sti. Teclı. $\Delta 7,2339$ (1989).

14. C. Bergman, in "Ion Plating and Implamation", edited by R. F. Hoclman, American Society for Mctals, USA, 1986. (Proceedings of the ASM Conference on Applications of lon Plating and Implantation to Materials, June 3-5, 1985, Atlanta, GA).

15. P. A. Lindfors, loc. cit. [14].

16. One such manufacturer is Vac-Tec Systems, Inc., Boulder, CO.

17. G. A. Lyubinov and V. I. Rakhovskii, Sov. Phys. Usp. 21 (8), 693 (1978).

18. I. G. Brown, J. E. Galvin, and R. A. MacGill, Appl. Ihys, Lett. 47, 358 (1985).

19. I. G. Brown, J. E. Galvin, B. F. Gavin, and R. A. MacGill, Rev. Sci. Instrum. 57, 1069 (1986).

20. I. G. Brown, in "The Plıysies and Technology of Ion Sources", I. G. Brown editor, Wiley, N.Y., 1989.

21. I. G. Brown, B. Feinberg, and J. E. Galvin, J. Appl. Phys. 613, 4889 (1988).

22. X. Godechot and I. G. Brown, to be published.

23. J. Sasaki and I. G. Brown, J. Appl. Phys. 66, 5198 (1989).

24. D. T. Tuma, C. L. Chen and D. K. Davies, J. Appl. Ihys. 49, 3821 (1978).

25. J. E. Daalder, Physica 104C, 91 (1981).

26. 1. I. Akscnov, 1. I. Konovalov, E. E. Kudryaviseva, V. V. Kunchenko, V. G. Padialkat and V. M. Khoroshikh, Sov. Phys. Tech. Phys. 29(8), 893 (1984).

27. I. I. Aksenov, V. A. Beluus, V.G. Padalka and V. M. Khoroshikh, Sov. J. Platsmat Phys. 4(4), 425 (1978).

28. V. A. Osipov, V. G. Padalka, L. P. Sablev and R. I. Stupak, Jnsinum. and Exp. Techniques 21(6), 173 (1978).

29. 1. I. Aksenov, S. I. Vakula, V. G. Padalka, V. E. Strclnitski and V. M. Khoroshikh, Sov. Phys. Tech. Phys. 25(9), 1164, (1980).

30. S. Shalev and R. L. Boxman, LEEE Trans. Plisma Sci. RS-14, 59 (1986).

31. V. S. Voitsenya, A, G. Gorbanyuk, I. N. Onishchenko and B. G. Safrinov, Sov. Phys. - Tech. Phys. 2(2), $22 !(1964)$.

32. I. I. Aksenov, A. N. Beloklivostikov, V. G. Piddalka, N. S. Repialov ind V. M. Khoroshikh, Plasma Physics and Controlled Fusion 28, 761 (1986)

33. J. Storer, J. E. Galvin and I. G. Brown, J. Appl. Phys. 66, 5245 (1989). 